\title{
Transient Dynamic Impact Suppression of a Baja Chassis Using Frontal and Rear Shock Absorbers
}

\author{
K. M. Goher ${ }^{1}$, Kong Chenhui ${ }^{2}$, S. O. Fadlallah ${ }^{3}$, A. H. Al Shabibi ${ }^{4}$ and N. Z. Al Rawahi ${ }^{4}$ \\ ${ }^{1}$ Department of Informatics and Enabling Technologies, Lincoln University, New Zealand, Corresponding author \\ email: Khaled.Goher@lincoln.ac.nz \\ ${ }^{2}$ Mechanical Engineering Institute, University of Shanghai for Science and Technology \\ ${ }^{3}$ Mechanical Engineering Department, Auckland University of Technology, New Zealand \\ ${ }^{4}$ Department of Mechanical and Industrial Engineering, College of Engineering, Sultan Qaboos University, Oman
}

\begin{abstract}
This paper investigates the behavior of impact loading on a Baja vehicle chassis with frontal and rear shock absorbers, using transient dynamic analysis under different assumptions of contact conditions. Using a Baja car, a transient dynamic impact is performed in ANSYS Workbench 14.0, where the maximum deformation, stress, and strains are calculated over duration of the particular impact. The mathematical model of the chassis is derived based on Kelvin model in order to design the best parameters of stiffness and damping coefficient in shock absorbers to minimize the deformation of the frame with the same impact. To study the effects of shock absorber under loading on a vehicle chassis, multiple finite element simulations are performed with different methodologies. Each methodology uses a different assumption on loading and boundary conditions, which leads to different results.
\end{abstract}

Keywords: Finite element analysis, Baja car, impact analysis, frontal and rear impact, crashworthiness

\section{INTRODUCTION}

Road traffic injuries are a global public health problem, with an estimated 1.2 million deaths and 50 million nonfatal injuries per year (Peden et al. [1]). The most direct way to observe how a car behaves during a collision and to assess its crashworthiness is to perform a crash test. Vehicle users' safety is one of the great concerns of everyone who is involved in the automotive industry. Therefore, it is advisable to establish a vehicle crash model and use its results instead of full-scale experiment measurements to predict car's behaviour during a collision. Crashworthiness is the ability of a vehicle to withstand a collision and to prevent the occupants from injuries in the event of a vehicular accident. It is one of the most important criteria employed in designing and evaluating a vehicle or a vehicle component. In the modern automotive industry, vehicle manufacturers make vast use of computer modelling and simulation to test crashworthiness and safety features in new designs.

\subsection{Crash Modelling and Simulation}

By building a finite element model (FEM) of a vehicle/component and run simulation on the computer, vehicle manufacturers can save lots of time, effort, and cost that would otherwise be required to build a unique prototype and test it. Important crashworthiness characteristics and safety features of their designs can be estimated and reflected from the computer analysis results. By developing both software and hardware, it is possible to use more analytical facilities, making several tools, for analytical designing of modern structure of a vehicle. Therefore, engineers are able to meet their growing needs and better performance of crashworthiness and safe driving. These tools include lumped parameters models (LPMs), beam element models (BEMs), hybrid models, and finite elements models (FEMs). Although these tools differ in complexity, each is based on the principles of structural mechanics that satisfy conservation of mass, momentum, and energy. The selection of a particular analysis tool depends on the task and on the particular design phase according to considered performance. 
In the 1970s, a relatively simple mass-spring-damper nonlinear system, known as the LMS (Lumped Mass Spring) model, was used to simulate a frontal impact test of a vehicle (Kamal [2]). Cheng et al. [3] presented an overview of the first computer simulations in vehicle collision and occupant kinematic analysis. Spethmann et al. [4] analysed the influence of virtual crash simulation tools in the last 35 years on automotive research and product development. Cho et al. [5] investigated ways to maximise the crash energy absorption by crash trigger in the frontal impact of a vehicle front frame.

Finite-element analysis has been widely applied to the simulation of vehicle crash. Several research studies investigated how to develop a full vehicle model for crashworthiness analysis by FEA (Cheng et al. [6]; Gursel and Nane [7]; Atahan [8]). Borovinsek et al. [9] provided a brief overview of different types of vehicle collisions. Crash FEMs are often the first detailed models developed in the design process of road cars (Donders et al. [10]). Usually, the crash models are first validated by the corresponding impact tests at the component level (Kirkpatrick [11]) and material plasticity parameters are the major focus. The discrepancies between FEM and actual vehicle structure usually come from, on the hardware side, missing parts, initial parts penetration, geometric variation, welding characteristics; on the FEM side, material properties, element quality, concentrated mass distribution, etc. (Cheng et al. [6]).

Cosme et al. [12] performed specific case studies in the design and analysis of heavy-duty frames. Karaoglu and Kuralay [13] performed stress analysis of a truck chassis by using FEM. LS-DYNA is an explicit code highly capable of solving high-speed impact problems that requires small time steps, which is commonly used by researchers in vehicle modelling, analysis and crashworthiness evaluation (Mei and Thole [14]). Argyris et al. [15] and Argyris et al. [16] presented the theoretical background for implicit finite element (FE) formulation and proposed a crash test analysis using simplified shell elements. The first published simulation of a vehicle frontal impact dates back to 1986, when Haug et al. [17] simulated a frontal crash of a Volkswagen Polo. Jenefeldt and Thomson [18] investigated the methodology to match frontal stiffness levels for vehicles in frontal impacts with different mass ratios. As for Thomson et al. [19], their study focused on car-to-car frontal crash compatibility.

\subsection{Car Modelling}

FEMs of vehicles and vehicle components have been increasingly applied in preliminary design analysis, vehicle crashworthiness evaluation, and component design. The first successful lumped parameter model for the frontal crash of an automobile was developed by Kamal [2]. Pawlus et al. [20] proposed a basic mathematical model to represent a collision together with its analysis. The first collision simulation model was developed to run on a digital computer in the mid-seventies (York and Day [21]). Finite element analysis was then introduced to calculate the complicated deforming process in crashes (Happian-Smith [22]). Current approach to car crash simulation is usually based on finite element analysis with an emphasis on better performance and safety, and thus, reducing the risk of fatal injuries during an accident (Genta [23]). Number of researchers have created high fidelity vehicle models for crash simulation and analysis: for a Chevrolet Silverado pick-up truck (Soltani et al. [24]), for a Honda Accord DX Sedan (Cheng et al. [6]), for both Toyota Yaris passenger car and Ford Explorer SUV (Mongiardini et al. [25]), and for Ford Crown Victoria (Kirkpatrick [11]) to study the effect on the overall crash safety of lightweight passenger cars.

This paper investigates the usability of springs, which exhibit nonlinear force-deflection characteristic, in the area of mathematical modelling of vehicle crash. We present a method, which allows obtaining parameters of the springmass model basing on the full scale experimental data analysis for a Baja car chassis. Since vehicle collision is a dynamic event, it involves such phenomena as rebound and energy dissipation. Three different spring unloading scenarios (elastic, plastic, and elasto-plastic) are covered and their suitability for vehicle collision simulation is evaluated. Subsequently, we assess which of those models fits the best to the real car's behaviour not only in terms of kinematic responses but also in terms of energy distribution. This paper is organised in 4 different sections. Section I gives a short description of the objective and the problem. In section II, the mathematic model was chosen and the method of impact force calculation was displayed along with all the settings related to modelling and dynamic analysis procedure. Results of the dynamic analysis are shown in section III. Finally, section IV contains the conclusion of this project. 


\section{CHASSIS MODELLING}

There are several software packages that are equipped to handle the crash-testing of vehicles but one of the most popular is from ANSYS Software Inc. called ANSYS Workbench. With Explicit dynamics application, automotive companies and their suppliers can test car designs without having to tool or experimentally test a prototype, thus saving time and expense (Ohashi [26]). But the explicit dynamic solver doesn't support spring and damper connection (Hallquist [27]), considering the shock absorbers in our project, transient structural solver is chosen to simulate the collision. Unlike in explicit solver, in transient structural solver all solid has to be set as flexible, including chassis, bumper and wall. So the problem is when the real collision happens, the wall is supposed to be rigid. To solve this problem, the initial velocity on the bumper is set instead of using the rigid wall to hit the chassis.

\subsection{SOLIDWORKS Modelling}

The commonly followed steps for modelling a vehicle assembly can be defined as follows: dimension definition, sketching, chassis and bumper modelling, and connection modelling and assembly. Using SOLIDWORKS, a full scale Baja vehicle is created as shown in Fig. 1. The entire components of the Baja vehicle are chassis frame, the engine, transmission, steering, tire assembly, and the driver. First of all is the chassis frame or roll cage (Fig. 1(b)). The roll cage must be a space frame of tubular structural steel with $25 \mathrm{~mm}$ outer diameter and $21 \mathrm{~mm}$ inner diameter. The mechanical properties of the structural steel employed in developing the vehicle's frame are listed in Table 1. Other design of the roll cage is heavily influenced by the safety rules set out by the SAE Baja competition organizers. The roll cage is modelled as $1800 \mathrm{~mm}$ long, $1000 \mathrm{~mm}$ high, and $600 \mathrm{~mm}$ wide. To simplify the model, several components of the vehicle are not modelled, but rather are represented as point masses and rigid bodies, such as transmission, steering and engine. This study is dealing with a linear direct impact, where model geometry is less important - rather component properties and meshing are crucial. But some components are all interconnected to each other, which won't be simplified like suspension and bumper. The bumper is $15 \mathrm{~mm}$ thick, $300 \mathrm{~mm}$ high, and $600 \mathrm{~mm}$ wide.

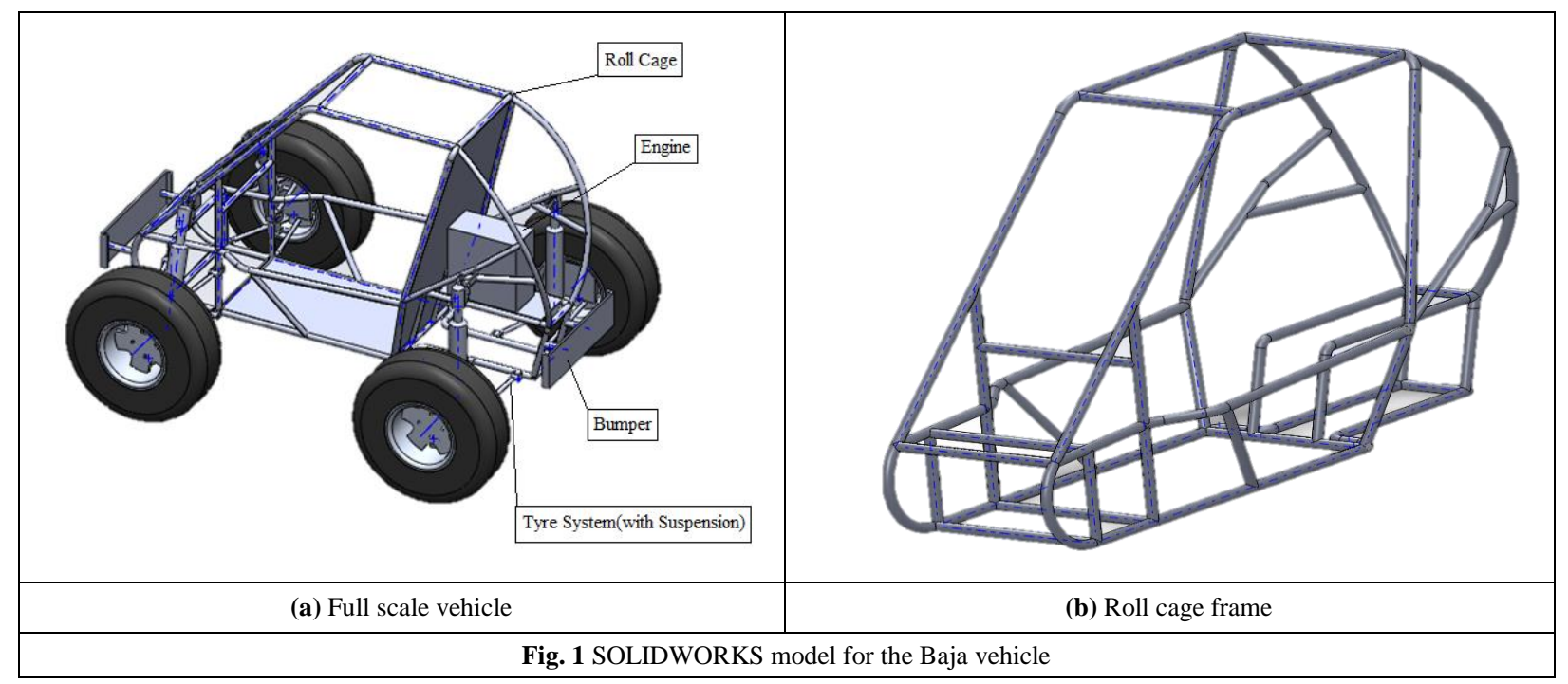

Table 1: Mechanical properties of structural steel employed in designing the Baja vehicle's frame

\begin{tabular}{|c|c|c|}
\hline Mechanical property & Value & Unit \\
\hline Density $(\rho)$ & 7850 & $\mathrm{~kg} / \mathrm{m}^{3}$ \\
\hline Modulus of Elasticity $(E)$ & $2.0 \times 10^{11}$ & $\mathrm{~Pa}$ \\
\hline Shear Modulus $(G)$ & $7.6923 \times 10^{10}$ & $\mathrm{~Pa}$ \\
\hline Poisson's ratio $(v)$ & 0.3 & \\
\hline
\end{tabular}




\begin{tabular}{|c|c|c|}
\hline Tensile Yield Strength $\left(\sigma_{T(\text { yield })}\right)$ & $2.5 \times 10^{8}$ & $\mathrm{~Pa}$ \\
\hline Compressive Yield Strength $\left(\sigma_{C(\text { yield })}\right)$ & $2.5 \times 10^{8}$ & $\mathrm{~Pa}$ \\
\hline Tensile Ultimate Strength $\left(\sigma_{T(u \mathrm{ult})}\right)$ & $4.6 \times 10^{8}$ & $\mathrm{~Pa}$ \\
\hline
\end{tabular}

\subsection{Kelvin Model}

Kelvin model is an element in which mass is attached to spring and damper which are connected in parallel. This model can be utilized to simulate the vehicle to vehicle collision, vehicle-to-barrier collision as well as for component impact modelling. Fig. 2 presents a kelvin model of a vehicle-to-barrier impact where $(k)$ is spring stiffness, $(c)$ is damping coefficient, $(m)$ is the vehicle's mass, and $\left(v_{\text {inital }}\right)$ is the initial impact velocity.

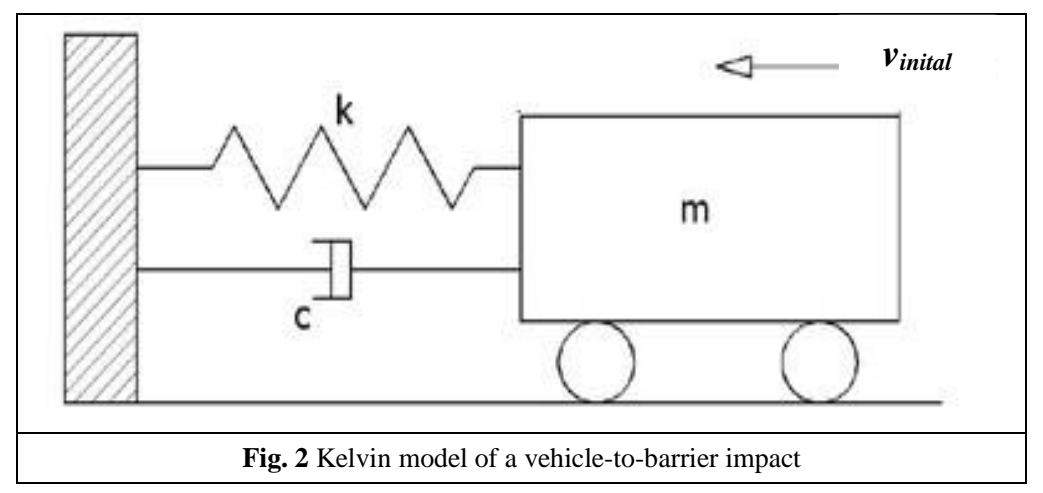

Pawlus et al. [20] illustrated the analytical method to obtain the structural parameters $k$ and $c$ in terms of damping factor $(\zeta)$ and the structure's natural frequency $(f)$ in the following set of equations:

$$
\begin{aligned}
& k=4 \pi^{2} f^{2} m \\
& c=4 \pi f \zeta m
\end{aligned}
$$

\subsection{Frontal / Rear Impact Transient Dynamic Analysis}

In this study, three scenarios will be considered in the transient dynamic approach: frontal impact only (Fig. 3(a)), rear impact only (Fig. 3(b)), and both frontal and rear impacts (Fig. 3(c)). For the first two scenarios, an initial velocity is applied to the mass of the vehicle. As shown in Fig. 3(a) and Fig. 3(b), the vehicle moves forwards or backwards at a constant speed until it strikes the rigid wall. As for the third scenario, combined frontal and rear impacts, two vehicles with the same initial speed from both sides collide with the middle vehicle. In this study, it is assumed that the shock absorber in the collision side is capable of absorbing the energy during the impact.

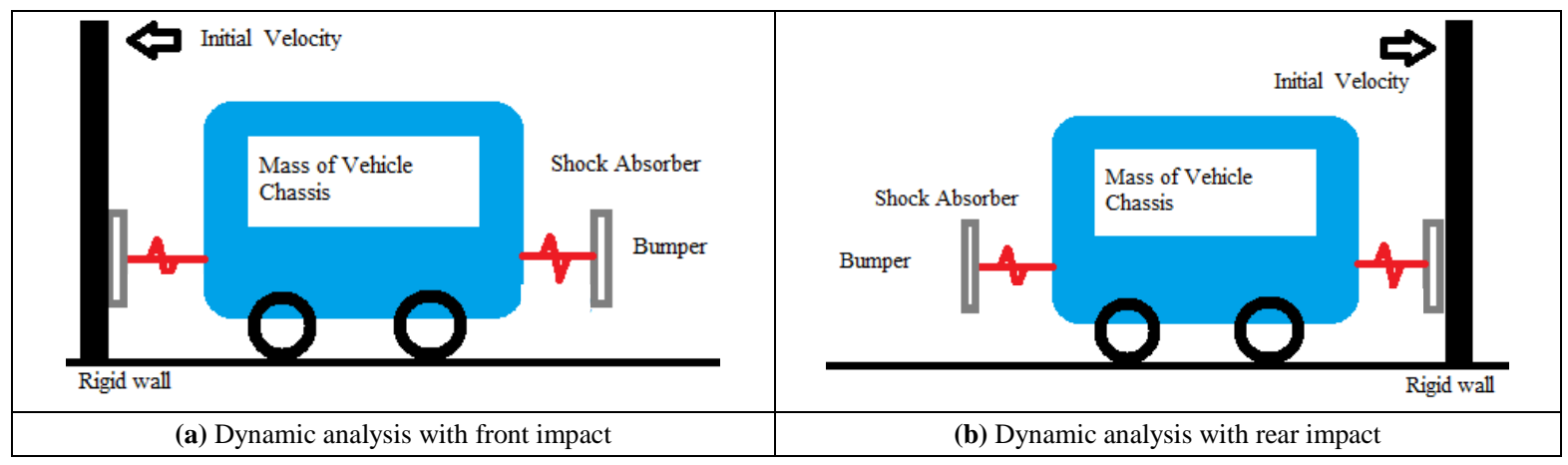




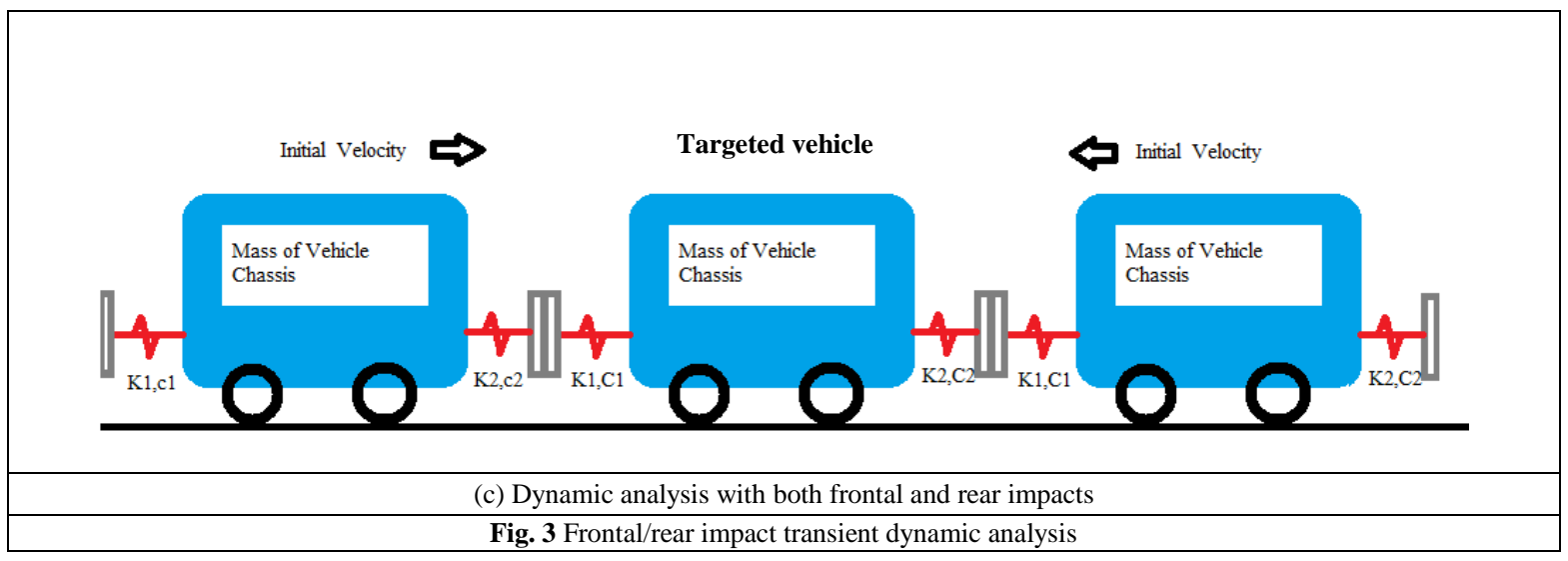

\subsection{Impact Force Evaluation}

The impact force, for a perfectly inelastic collision, can be estimated using the below equations (Nagurbabu [28]):

$W_{N E T}=\frac{1}{2} m v_{\text {final }}^{2}-\frac{1}{2} m v_{\text {initial }}^{2}$

$W_{N E T}=F \times d$

Eq. 3 states that the variation in kinetic energy is equal to the net work done $\left(W_{N E T}\right)$, and the work needed to stop the car (Eq. 4) is equal to the impact force $(F)$ times the distance $(d)$. Combining these two equations, and given the fact that the final impact velocity $\left(v_{\text {final }}\right)$ is zero, leads to the following:

$F=-\frac{1}{2} m v_{\text {initial }}^{2} \times\left(\frac{1}{d}\right)$

Since $d=v_{\text {initial }} \times t$, substituting this in Eq. 5 leads to:

$F=-\frac{1}{2} m v_{\text {initial }} \times\left(\frac{1}{t}\right)$

With the information of the vehicle's total mass $(m)$, initial impact velocity $\left(v_{\text {initial }}\right)$, and considering that the vehicle comes to rest 0.1 seconds after the impact $(t=0.1 \mathrm{sec})$, the impact force $(F)$ can be calculated.

The weights of all the components of the Baja vehicle are evaluated as shown in Table 2 and equivalent weights are modelled in the form of solid rigid blocks. Considering the vehicle's initial speed is $70 \mathrm{~km} / \mathrm{hr}(19.4 \mathrm{~m} / \mathrm{s})$, and with the total weight of all components, the impact force $(F)$ can be calculated using Eq. 6 :

$F=\frac{1}{2} \times 272.1 \times(19.4) \times\left(\frac{1}{0.1}\right)=26,460 \mathrm{~N}$

At this stage of the research, with a design factor of safety of (1.2), the current frame design is aimed at withstanding an impact load of 31,752 $\mathrm{N}$ in minimum. 
Table 2: Weight of components of the Baja vehicle (Nagurbabu [28])

\begin{tabular}{|l|c|}
\hline \multicolumn{1}{|c|}{ Component } & $\begin{array}{c}\text { Weight } \\
\text { (kg) }\end{array}$ \\
\hline Equivalent mass of chassis (including body sheet and gussets) & 54.4 \\
\hline Equivalent mass of engine (Briggs \& Stratton 10 hp) & 27.2 \\
\hline Equivalent mass of tire assembly (includes suspension) & 45.4 \\
\hline Equivalent mass of transmission & 27.2 \\
\hline Equivalent mass of steering, brakes, and auxiliary & 27.2 \\
\hline Equivalent mass of driver & 90.7 \\
\hline Total mass & $\mathbf{2 7 2 . 1}$ \\
\hline
\end{tabular}

\subsection{Finite Element Modelling and Contact Setting}

After developing the SOLIDWORKS model for the Baja vehicle, the model has been transferred to ANSYS Workbench transient solver where the finite element model has been created as can be seen in Fig. 4. Mesh sensitivity has been examined and with approximately 37729 mesh elements, simulation results insignificantly changes with decreasing element size and gives good results without increasing both CPU time and memory requirements.

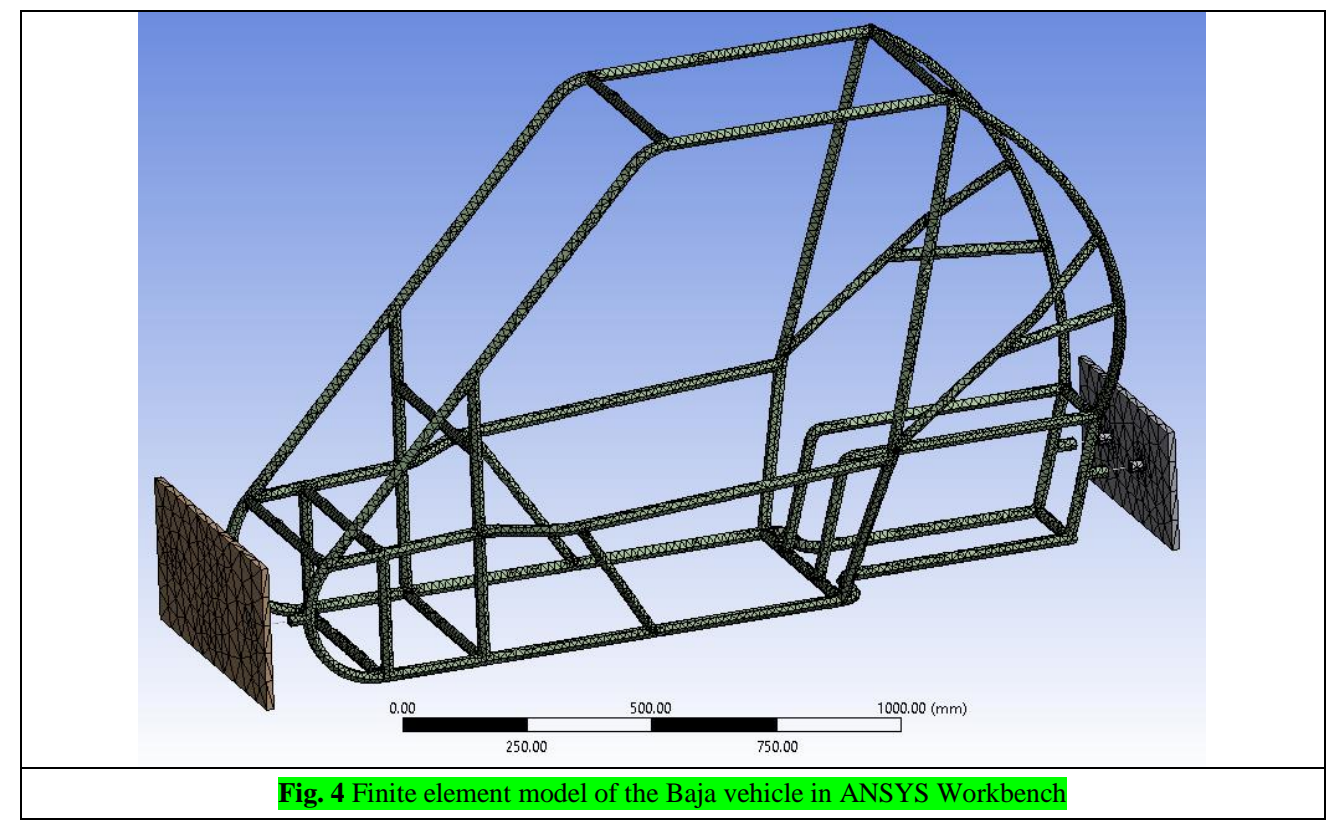

Moving to contact settings and in ANSYS Workbench transient solver, the two surfaces between the chassis and the bumper are linked as the longitude of the shock absorber. In this study, the shock absorber's longitude is set to 0.05 m.

The absorber's critical material properties, spring stiffness $(k)$ and damping coefficient $(c)$, need to be manually inserted into the software from a series of data calculated prior performing simulations. By setting the ratio between stiffness and damping ration to be $0.1(\mathrm{k} / \mathrm{c}=0.1)$, a series of $k$ and $c$ values is generated in order to figure out the best possible values. Initially, for the first stage, the stiffness values are incremented by 20 . Then, and by focusing 
on the maximum deformation drop in the deformation-stiffness plot, the step size in the stiffness values is decreased till obtaining the optimal values. Table 3 provides an example of the process of seeking the best parameters.

Table 3: Example process of seeking the best parameters by varying stiffness values

\begin{tabular}{|c|c|c|c|}
\hline Stage 1 & Stage 2 & Stage 3 & Stage 4 \\
\hline $20 \mathrm{~N} / \mathrm{mm}$ & $100 \mathrm{~N} / \mathrm{mm}$ & $120 \mathrm{~N} / \mathrm{mm}$ & $124 \mathrm{~N} / \mathrm{mm}$ \\
\hline $40 \mathrm{~N} / \mathrm{mm}$ & $105 \mathrm{~N} / \mathrm{mm}$ & $122 \mathrm{~N} / \mathrm{mm}$ & $124.5 \mathrm{~N} / \mathrm{mm}$ \\
\hline$\ldots$ & $\ldots$ & $\ldots$ & $\ldots$ \\
\hline $200 \mathrm{~N} / \mathrm{mm}$ & $140 \mathrm{~N} / \mathrm{mm}$ & $130 \mathrm{~N} / \mathrm{mm}$ & $128 \mathrm{~N} / \mathrm{mm}$ \\
\hline
\end{tabular}

The function of the boundary conditions is to create and define constraints and loads on finite element models. To define the loading process, the vehicle's velocity is transferred to the reverse velocity of the bumper when the impact occurs (Fig. 5). As previously mentioned, the initial speed is set to $70 \mathrm{~km} / \mathrm{hr}(19.4 \mathrm{~m} / \mathrm{s})$ and it decreases to 0 in 0.1 seconds linearly.

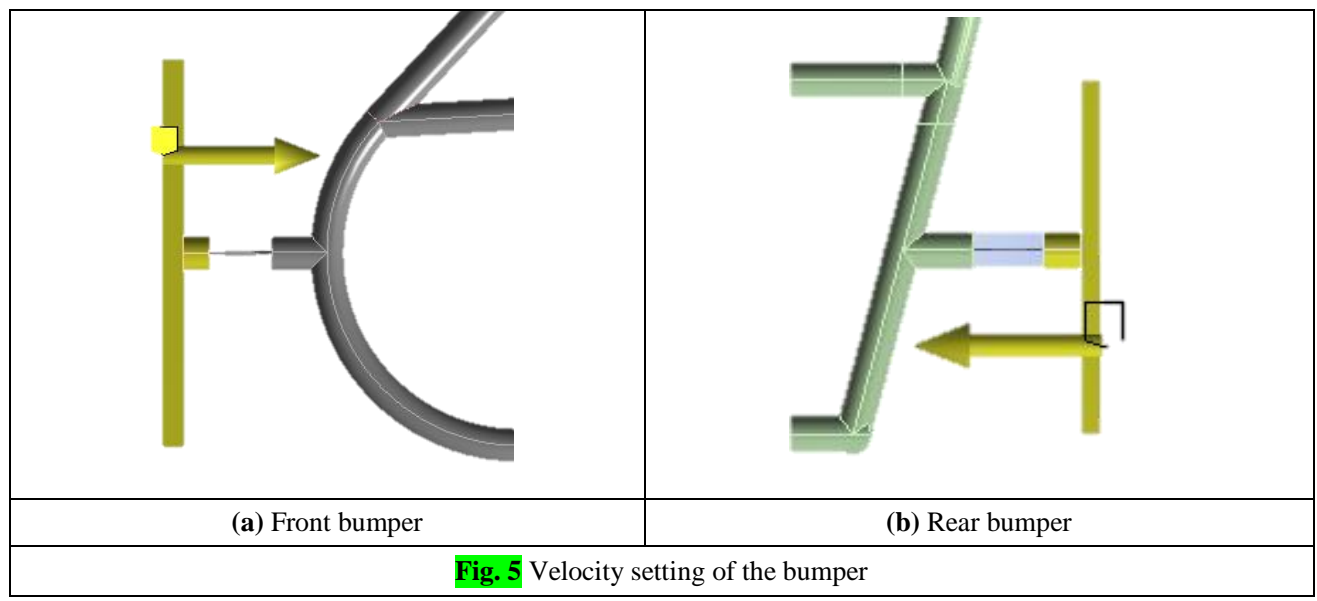

\subsection{Deformation, Stress, and Strain of the Chassis}

For the three collision scenarios: frontal impact only, rear impact only, and both frontal and rear impacts, particular geometrical parts are considered in the analysis, as demonstrated in Fig (6), due to their impact on the occupant's safety:

- In frontal only collision, the highlighted beam of the front chassis (Fig. 6(a)) is the closet to the occupant. The deformation of this beam may endanger the occupant's head if he is not properly fixed to the seat.

- In rear only collision, the highlighted columns of the rear chassis (Fig. 6(b)) are just behind the occupant seat. The deformation of these columns may endanger the occupant's back if the seat cannot absorb all the collision energy.

- In frontal and rear collision, both highlighted features should be considered. 


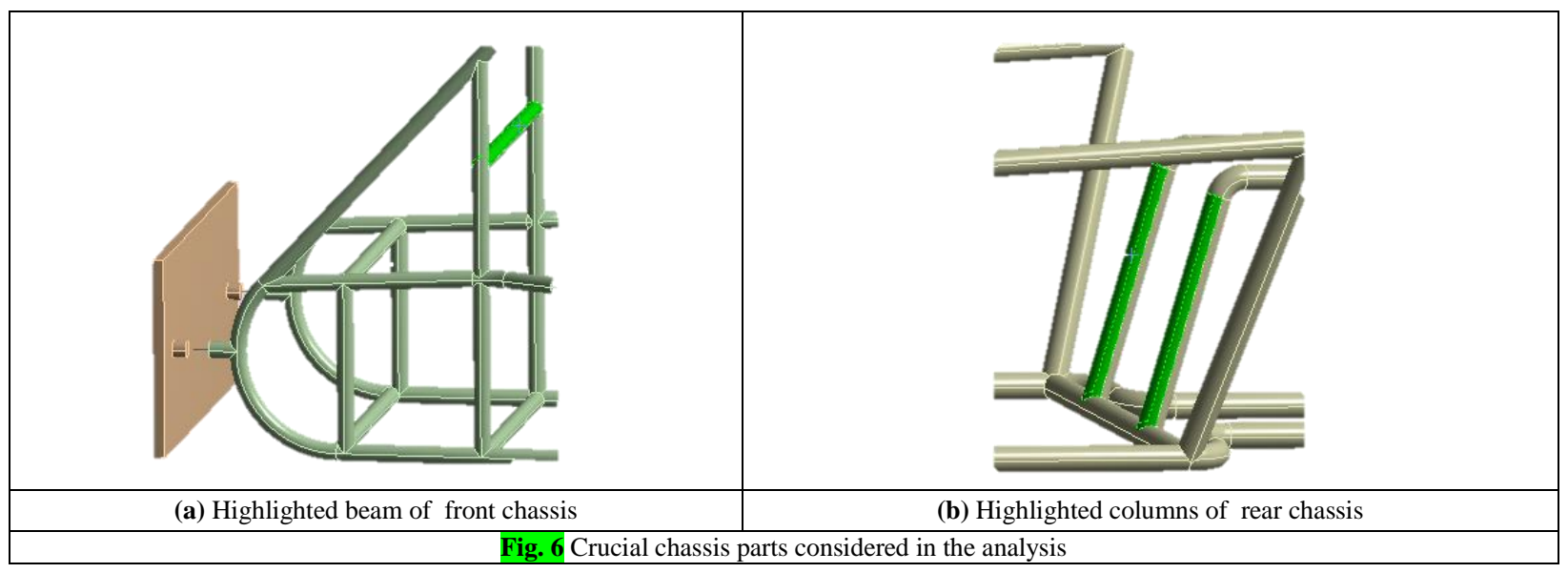

\section{RESULTS AND DISCUSSSION}

\subsection{Frontal Collision Only}

Fig. 7 illustrates the Baja chassis' front beam deformation for the scenario where the vehicle moves forwards at a constant speed $(70 \mathrm{~km} / \mathrm{hr})$ until it strikes a rigid wall. For multiple stiffness values for the front shock absorber ranged between $k_{l}=20 \mathrm{~N} / \mathrm{mm}$ and $k_{l}=200 \mathrm{~N} / \mathrm{mm}$ (Fig. 7 (a)), the maximum deformation drop occurred in the stiffness range of 80-120 N/mm. Focusing on the located zone and with a step size of $5 \mathrm{~N} / \mathrm{mm}$ (Fig. 7 (b)), the front beam's maximum deformation drop occurred in the zone between $k_{l}=105 \mathrm{~N} / \mathrm{mm}$ and $k_{l}=115 \mathrm{~N} / \mathrm{mm}$. Repeating the previous step again by magnifying the targeted range and considering a $1 \mathrm{~N} / \mathrm{mm}$ increment in the stiffness values, it can be observed from Fig. 7 (c) that the minimum deformation took place at $k_{l}=113.5 \mathrm{~N} / \mathrm{mm}$. For this scenario, it can be concluded that the suitable stiffness value for the front shock absorber is approximately $k_{I}=113.5$ $\mathrm{N} / \mathrm{mm}$.

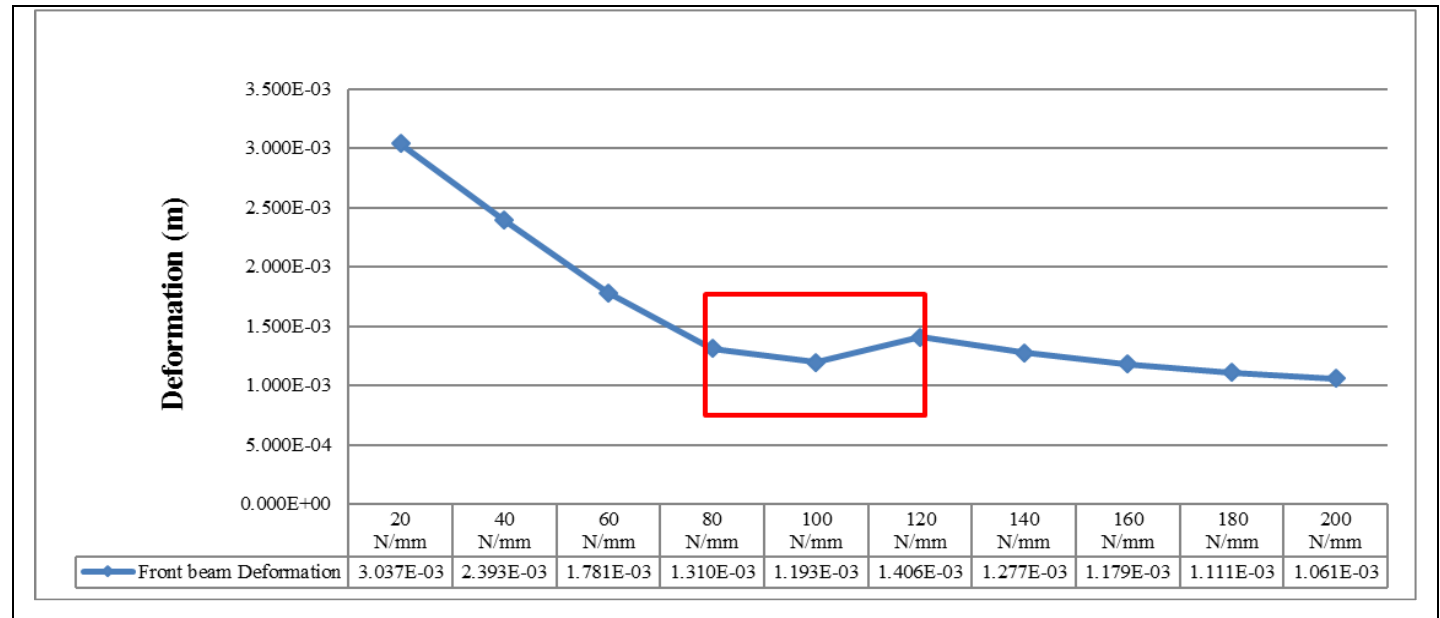

(a) Stiffness range $\left(20 \mathrm{~N} / \mathrm{mm}<k_{l}<200 \mathrm{~N} / \mathrm{mm}\right)$, Step size $(20 \mathrm{~N} / \mathrm{mm})$ 


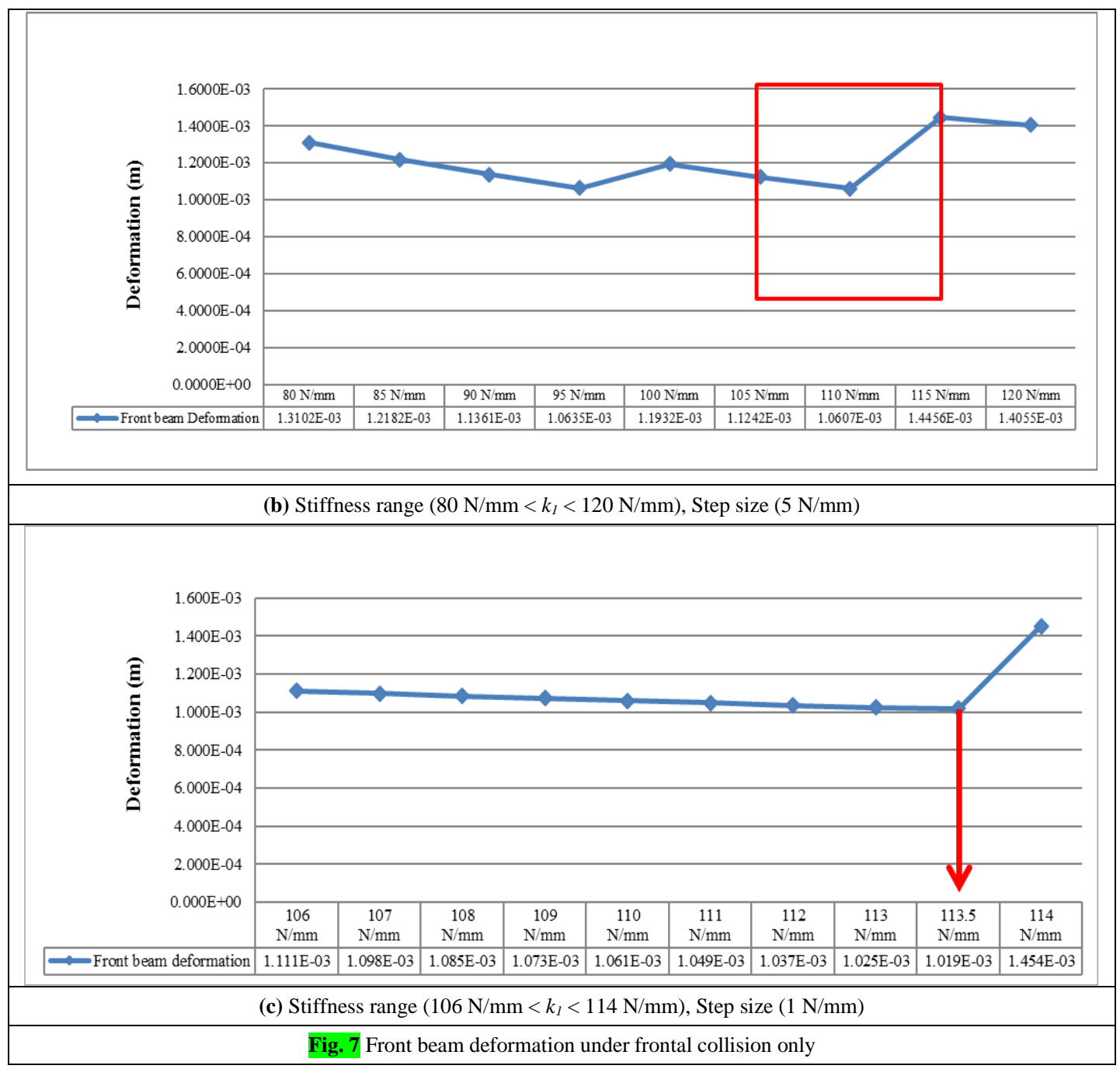

\subsection{Rear Collision Only}

For the case where the Baja car moves backwards at a constant speed $(70 \mathrm{~km} / \mathrm{hr})$ until it strikes a rigid wall, Fig. 8 demonstrates the vehicle chassis' rear columns deformation. For multiple stiffness values for the rear shock absorber in the range of $k_{2}=20 \mathrm{~N} / \mathrm{mm}$ and $k_{2}=200 \mathrm{~N} / \mathrm{mm}$ (Fig. 8 (a)), the minimum deformation was located in the zone between $k_{2}=102 \mathrm{~N} / \mathrm{mm}$ and $k_{2}=112 \mathrm{~N} / \mathrm{mm}$. Magnifying the specified range with a $2 \mathrm{~N} / \mathrm{mm}$ increment in the stiffness values (Fig. 8 (b)), the maximum deformation drop occurred in the stiffness range of 106-109.5 N/mm. Again, by repeating the same procedure but with a step size of $0.5 \mathrm{~N} / \mathrm{mm}$ (Fig. 8 (c)), the minimum deformation occurred at $k_{2}=108 \mathrm{~N} / \mathrm{mm}$. Therefore, for this scenario, the best stiffness value for the rear shock absorber is around $k_{2}=108 \mathrm{~N} / \mathrm{mm}$. 


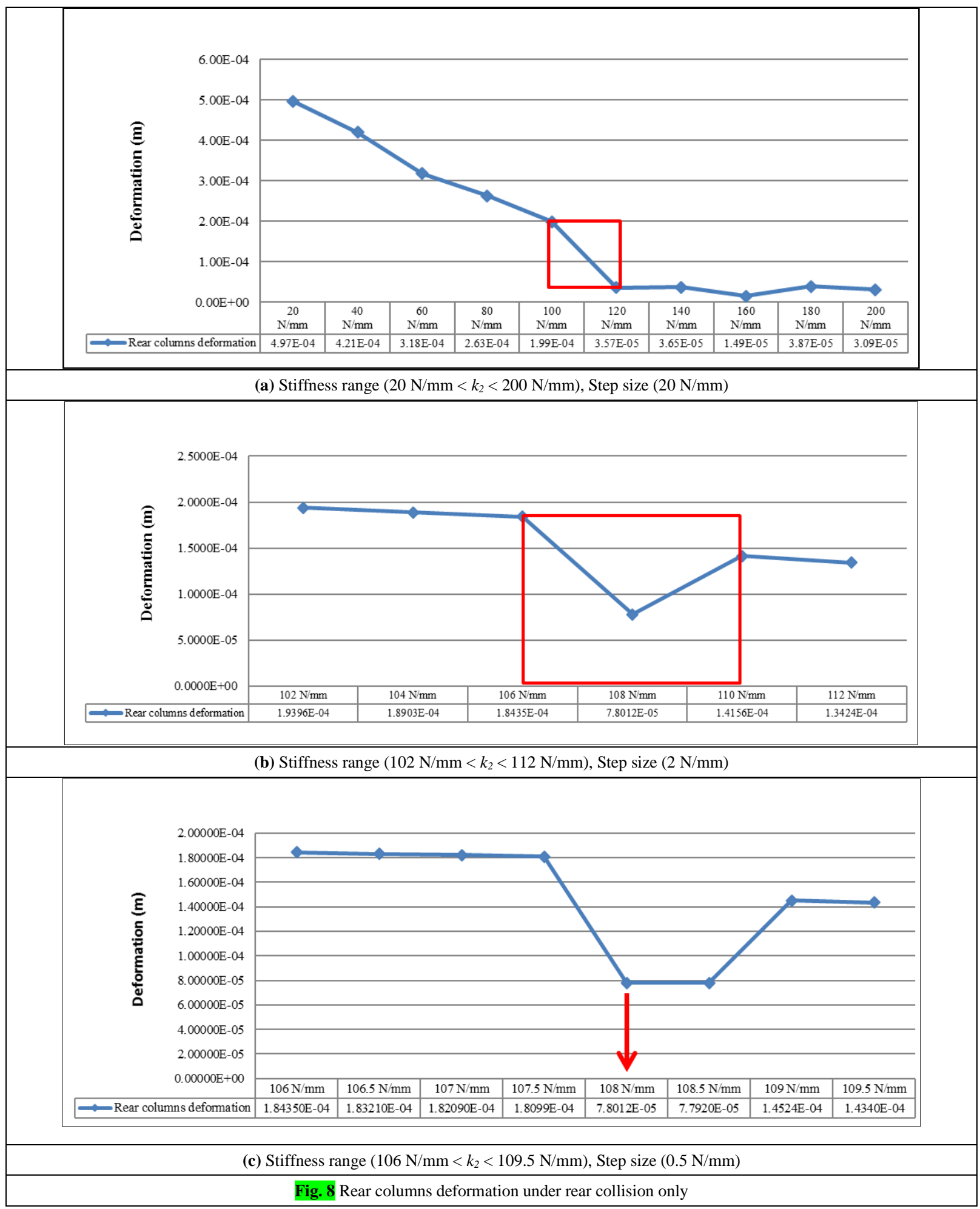

\subsection{Frontal and Rear Collision}

For this scenario, where the Baja vehicle collides with two vehicles with the same initial speed from both front and rear sides, two cases were investigated. The first case assumes that both front and rear shock absorbers have the 
same stiffness value $\left(k_{l}=k_{2}=k\right)$. As for the other case, it considers that the stiffness is different for the two shock absorbers $\left(k_{1} \neq k_{2}\right)$.

\subsubsection{Case $1\left(k_{1}=k_{2}=k\right)$}

For this case, the stiffness of both front and rear shock absorbers is considered to be the same $\left(k_{l}=k_{2}=k\right)$. Fig. 9 (a) shows the front beam and rear columns deformation under frontal and rear impact for multiple stiffness values for both front and rear shock absorbers varying between $k=60 \mathrm{~N} / \mathrm{mm}$ and $k=180 \mathrm{~N} / \mathrm{mm}$. Based on the previous results, the maximum deformation drop occurred between $k=100 \mathrm{~N} / \mathrm{mm}$ and $k=140 \mathrm{~N} / \mathrm{mm}$. Concentrating on the specified zone and setting a $5 \mathrm{~N} / \mathrm{mm}$ increment in the stiffness values (Fig. 9 (b)), the front beam and rear columns maximum deformation drop was located in the stiffness range of 125-132 N/mm. Focusing on the located segment and with a step size of $1 \mathrm{~N} / \mathrm{mm}$ (Fig. 9 (c)), the minimum deformation in both the front beam and the rear columns occurred when the stiffness value was at $k=131 \mathrm{~N} / \mathrm{mm}$. Based on the defined conditions, the suitable stiffness value for both front and rear shock absorbers is $131 \mathrm{~N} / \mathrm{mm}$.

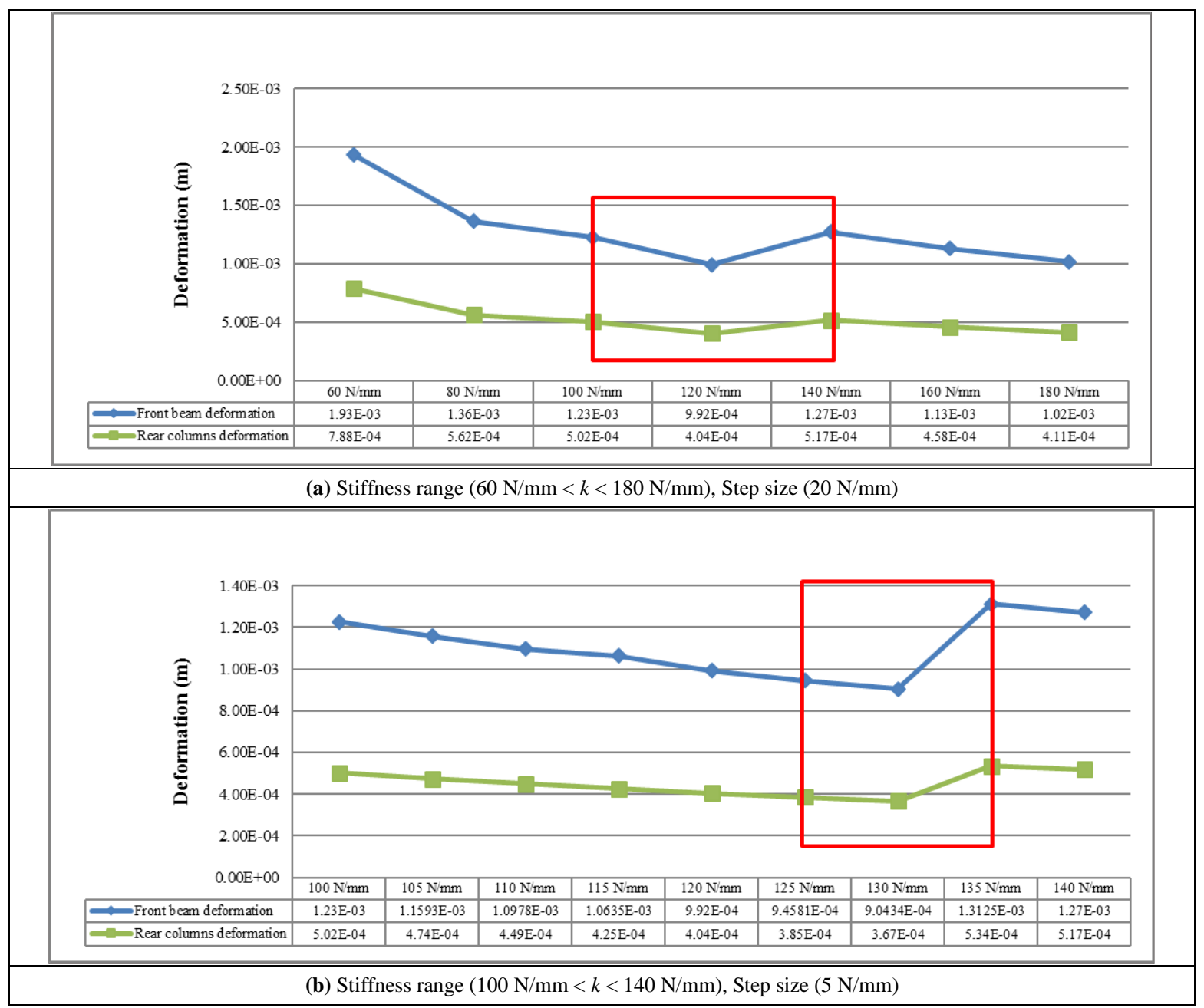




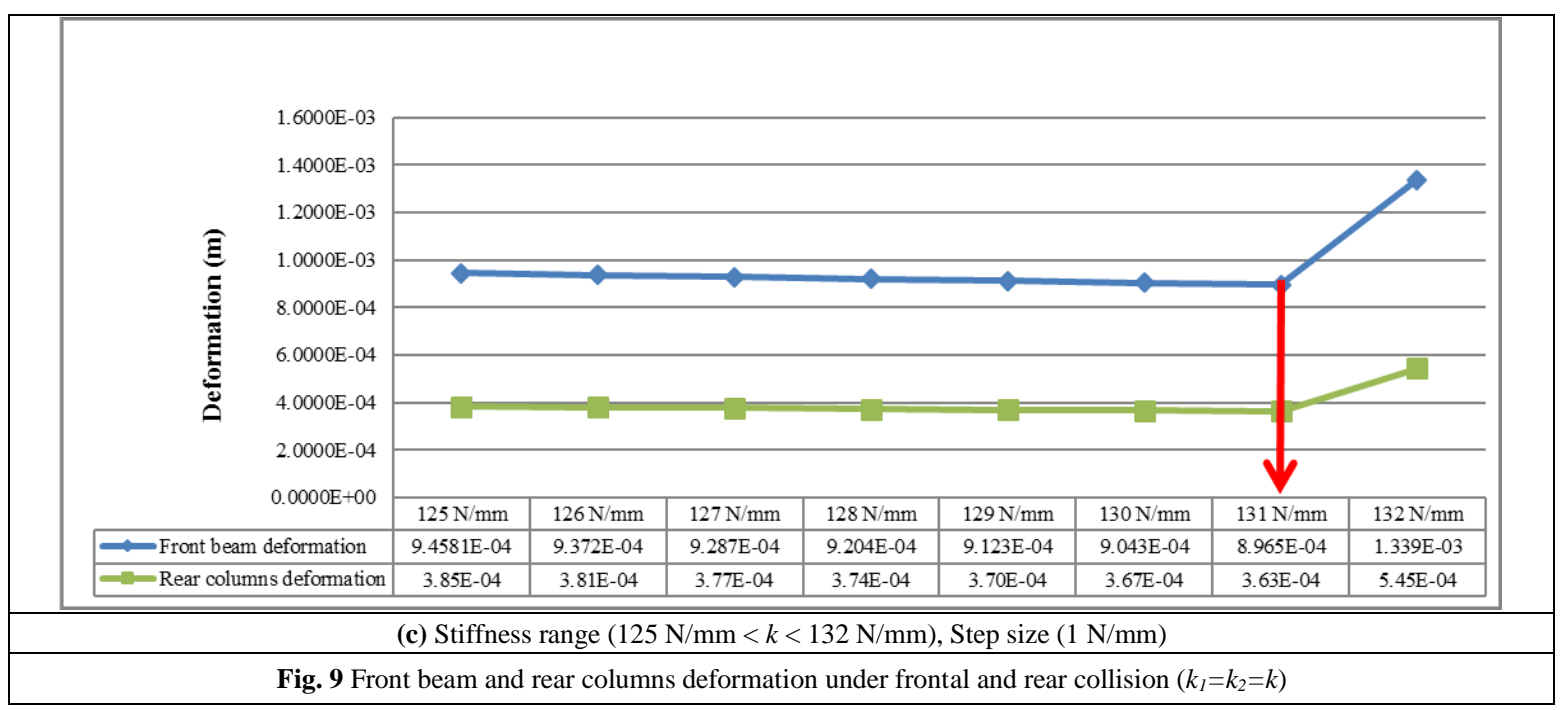

\subsubsection{Case $2\left(k_{1} \neq k_{2}\right)$}

The stiffness of both front and rear shock absorbers is considered to be different for this case $\left(k_{1} \neq k_{2}\right)$. It has been observed in the previous scenarios, frontal collision only and rear collision only, that the the stiffness of the front shock absorber is always greater than that of the rear shock absorber $\left(k_{1}>k_{2}\right)$. Therefore, and based on this observation, the rear shock absorber's stiffness $\left(k_{2}\right)$ was configured first and the obtained value was employed to seek the front shock absorber's stiffness $\left(k_{1}\right)$. Fig. 10 (a) demonstrates the front beam and rear columns deformation under frontal and rear collision for multiple stiffness values for the rear shock absorber varying between $k_{2}=40$ $\mathrm{N} / \mathrm{mm}$ and $k_{2}=200 \mathrm{~N} / \mathrm{mm}$. The maximum deformation drop occurred in the range of $k_{2}=130 \mathrm{~N} / \mathrm{mm}$ and $k_{2}=150$ $\mathrm{N} / \mathrm{mm}$. Focusing on the selected area and setting a $5 \mathrm{~N} / \mathrm{mm}$ increment in the stiffness values (Fig. 10 (b)), the minimum deformation in both front beam and rear columns took place at $k_{2}=145 \mathrm{~N} / \mathrm{mm}$. Using the obtained value of $k_{2}$, Fig. 10 (c) shows the front beam and rear columns deformation under frontal and rear collision for multiple stiffness values for the front shock absorber changing between $k_{l}=40 \mathrm{~N} / \mathrm{mm}$ and $k_{l}=200 \mathrm{~N} / \mathrm{mm}$. As can be seen, the range where the deformation reaches its minimum is within $150-180 \mathrm{~N} / \mathrm{mm}$. Zooming in the specified range (Fig. 10 (d)), the maximum deformation drop was located at $k_{l}=160 \mathrm{~N} / \mathrm{mm}$. Therefore, and according to the obtained results, the suitable stiffness values for both front and rear shock absorbers are $k_{l}=160 \mathrm{~N} / \mathrm{mm}$ and $k_{2}=145$ $\mathrm{N} / \mathrm{mm}$.

Fig. 11 represents ANSYS Workbench simulation results for both front beam and rear columns in terms of directional deformation, equivalent elastic strain, and equivalent stress after applying the obtained stiffness values of both front and rear shock absorbers. Based on the results, minimum deformation of the Baja chassis' front beam and rear columns were achieved, $0.14387 \mathrm{~mm}$ and $0.058255 \mathrm{~mm}$ respectively. 


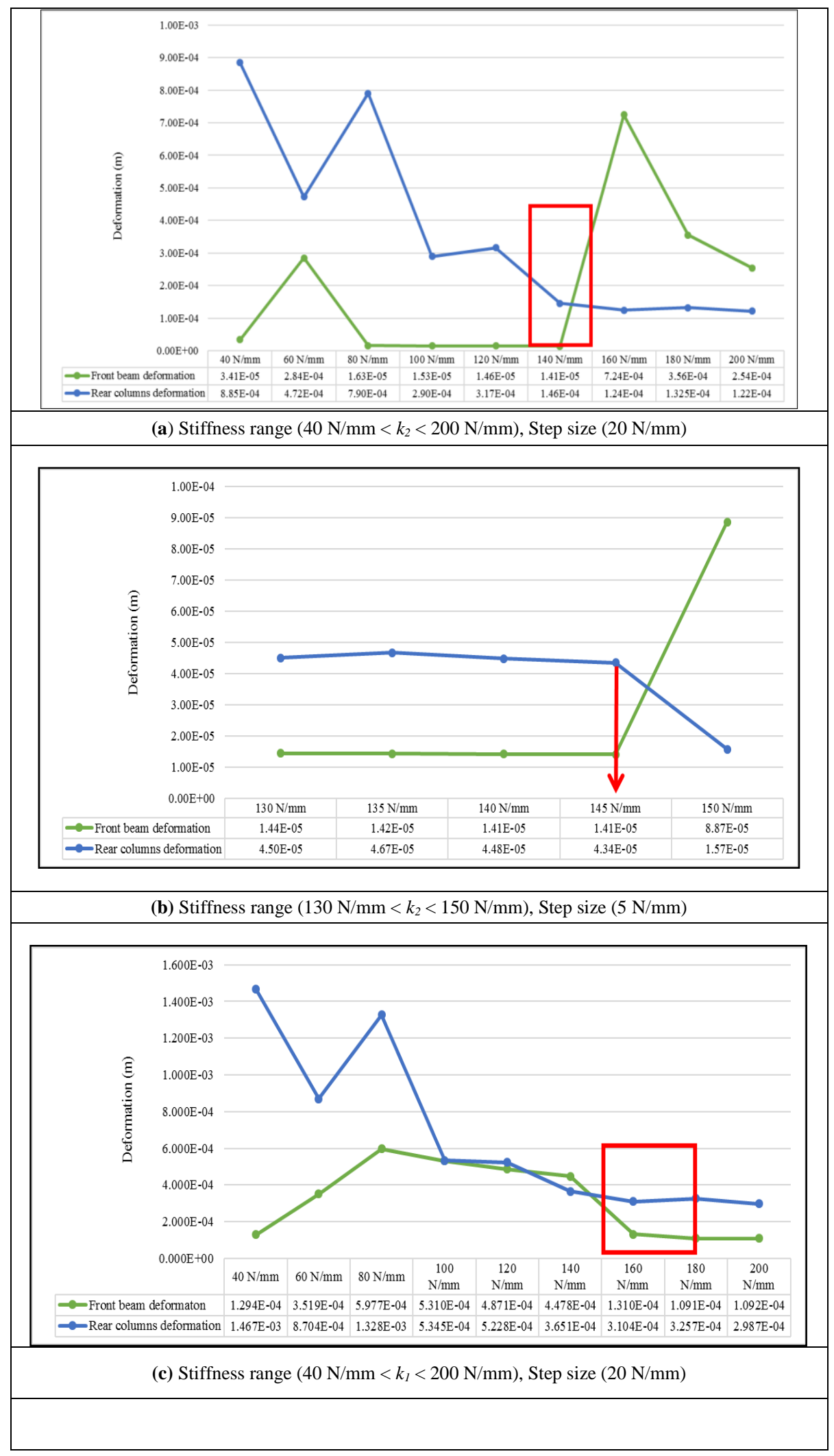




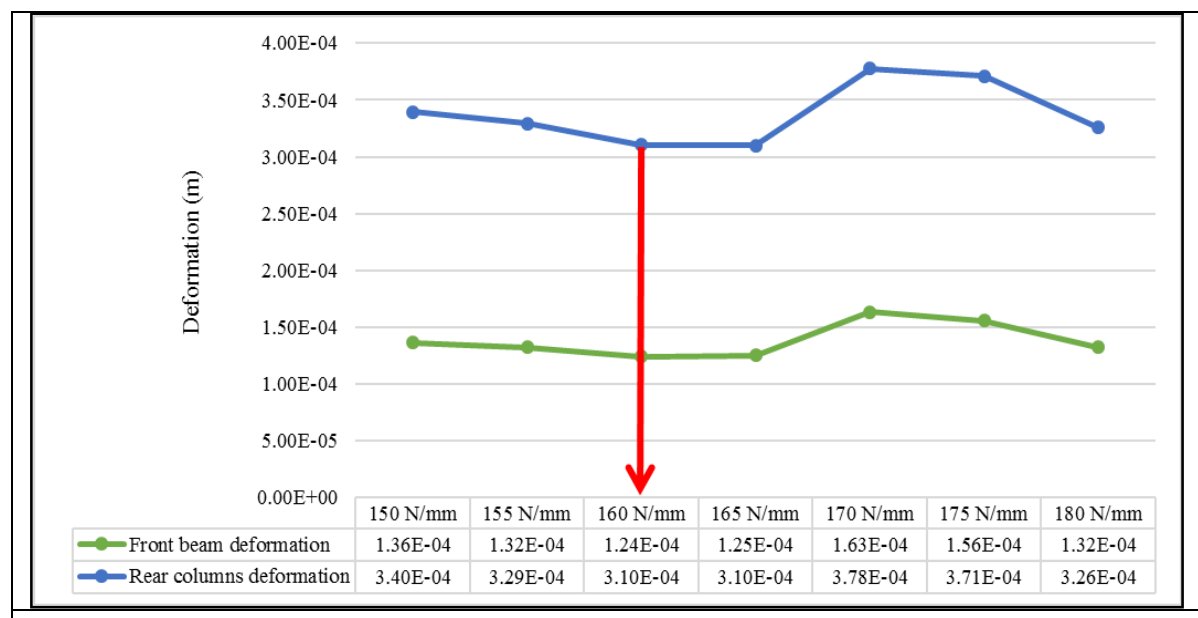

(d) Stiffness range $\left(150 \mathrm{~N} / \mathrm{mm}<k_{l}<180 \mathrm{~N} / \mathrm{mm}\right)$, Step size $(5 \mathrm{~N} / \mathrm{mm})$

Fig. 10 Front beam and rear columns deformation under frontal and rear collision $\left(k_{l} \neq k_{2}\right)$
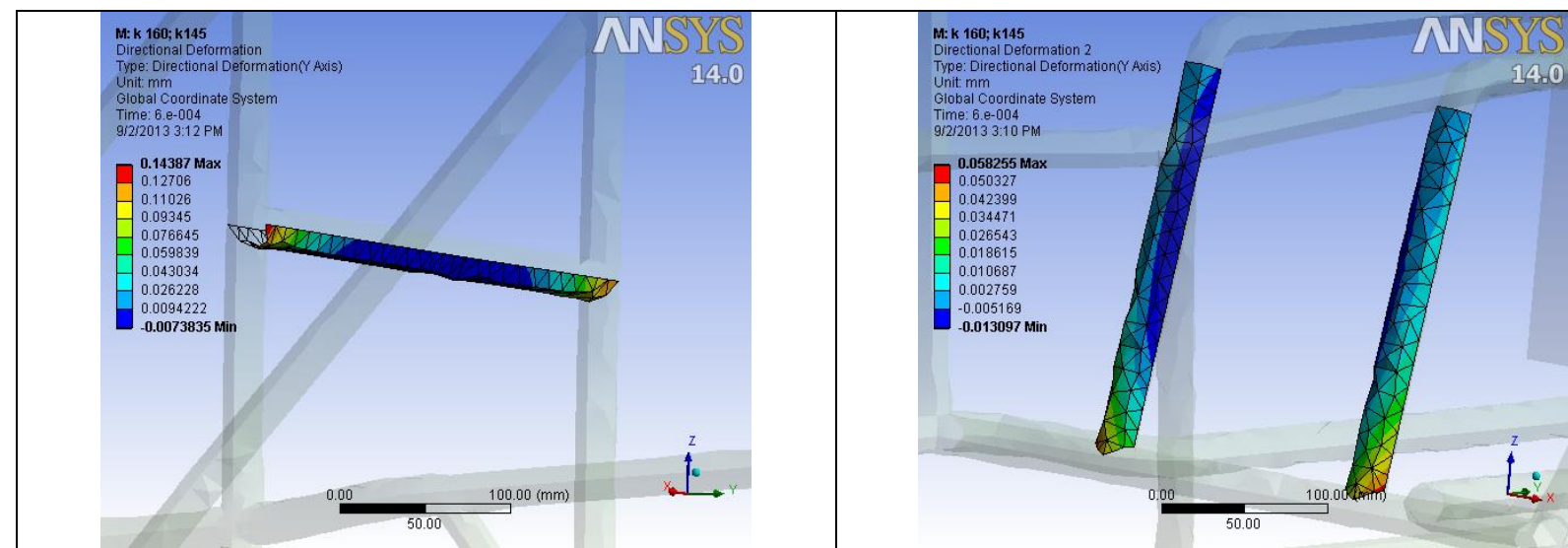

(a) Directional deformation

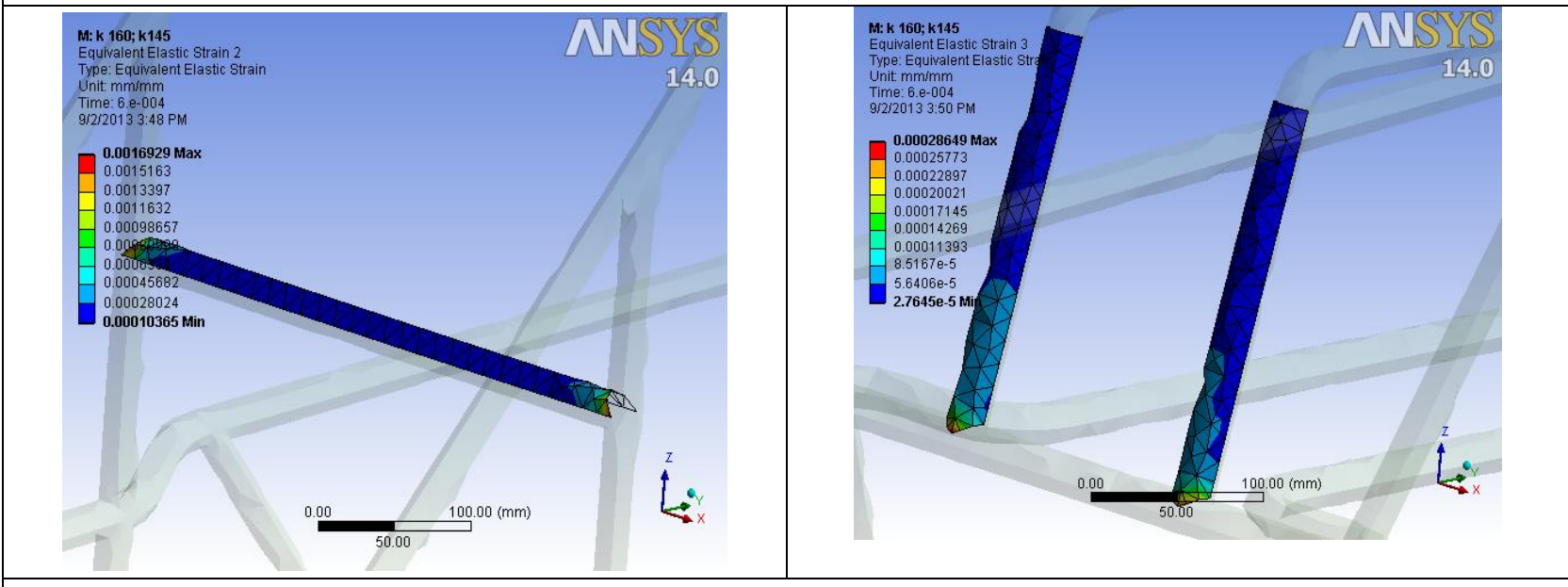

(b) Equivalent elastic strain 


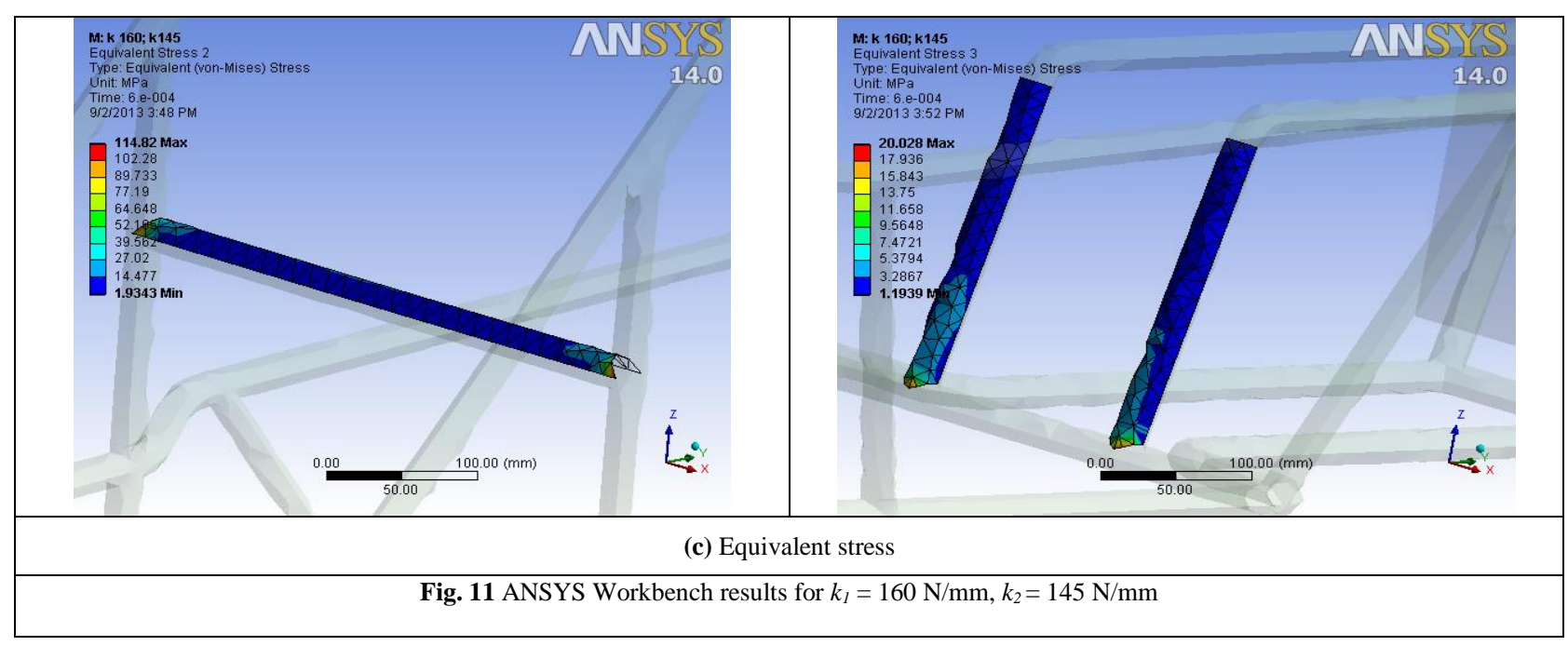

\section{CONCLUSION and FUTURE WORK}

The overall objective of the work was to seek the suitable parameters of stiffness and damping coefficient in shock absorbers employed to a Baja vehicle chassis. By utilizing ANSYS Workbench software package, simulations were performed. Due to the difficulty in transferring the actual Baja car model into ANSYS Workbench, a simplified model of the test vehicle was created and simulations were carried out for three scenarios: frontal impact only, rear impact only, and both frontal and rear impacts. According to simulation results, and based on the obtained values of stiffness for both frontal and rear shock absorbers, minimum deformation of the chassis' front beam and rear columns were achieved and therefore, it can be concluded that the Baja car's occupant would not be harmed by the deformation of the chassis' crucial parts. Future considerations of this work will consider increasing the model's complexity, investigating the effect of varying the impact speed on the vehicle's chassis, and validating the achieved simulation results with experimental ones.

\section{REFERENCES}

[1] Peden, M., Scurfield, R., Sleet, D., Mohan, D., Jyder, A. A., Jarawan, E., Mathers, C., (2004). World report on road traffic injury prevention. Geneva: WHO. Available at: <http://apps.who.int/iris/bitstream/10665/42871/1/9241562609.pdf>.

[2] Kamal, M. M., (1970). Analysis and simulation of vehicle to barrier impact. SAE Technical Papers, Technical Paper No. 700414.

[3] Cheng, P., Sens, M., Wiechel, J., Guenther, D., (1987). An overview of the evolution of computer assisted motor vehicle accident reconstruction, SAE Technical Paper No. 871991.

[4] Spethmann, P., Thomke, S.H., Herstatt, C., (2006). The impact of crash simulation on productivity and problem-solving in automotive R\&D, Working Paper No. 43, Technologie- und Innovations management, Technische Universit"at HamburgHarburg, Hamburg.

[5] Cho, Y. B., Bae, C. H., Suh, M. W., Sin, H. C., (2008). Maximisation of crash energy absorption by crash trigger for vehicle front frame using the homogenisation method, International Journal of Vehicle Design, 46, pp. 23-50.

[6] Cheng, Z. Q., Thacker, J. G., Pilkey, W. D., Hollowell, W. T., Reagan, S. W., Sieveka, E. M., (2001). Experiences in reverse engineering of a finite element automobile crash model, Finite Elements in Analysis and Design, 37, pp. 843-860.

[7] Gursel, K. T., Nane, S. N., (2010). Non-linear finite element analyses of automobiles and their elements in crashes, International Journal of Crashworthiness, 15, pp. 667-692.

[8] Atahan, A. O., (2016). Crashworthiness analysis of a bridge rail-to-guardrail transition, International Journal of Crashworthiness, pp. 1-12. 
[9] Borovinsek, M., Vesenjak, M., Ulbin, M., Ren, Z., (2007). Simulation of crash tests for high containment levels of road safety barriers, Engineering Failure Analysis, 14(8), pp. 1711-1718.

[10] Donders, S., Takahashi, Y., Hadjit, R., VanLangenhove, T., Brughmans, M., Van Genechten, B., Desmet, W., (2009). A reduced beam and joint concept modelling approach to optimize global vehicle body dynamics, Finite Elements in Analysis and Design, 45, pp. 439-455.

[11] Kirkpatrick, S.W., (2000). Development and validation of high fidelity vehicle crash simulation models, SAE Technical Papers.

[12] Cosme, C., Ghasemi, A., Gandevia, J., (1999). Application of computer aided engineering in the design of heavy-duty truck frames, SAE Transactions, Detroit, MI, USA, 1999-01-3760.

[13] Karaoglu, C., Kuralay, N. S., (2002). Stress analysis of a truck chassis with riveted joints, Finite Elements in Analysis and Design, 38, pp. 1115-1130.

[14] Mei, L. Thole, C. A., (2008). Data analysis for parallel car-crash simulation results and model optimization, Simulation Modelling Practice and Theory, 16, pp. 329-337.

[15] Argyris, J., Balmer, H. A., Doltsinis, J. St., Kruz, A., (1986). Computer simulation of crash phenomena, International Journal for Numerical Methods in Engineering, 22, pp. 497-519.

[16] Argyris, J., Balmer, H., Doltsinis I. St., (1988). Some thoughts on shell modelling for crash analysis, Computer Methods in Applied Mechanics and Engineering, 71, pp. 341-365.

[17] Haug, E., Scharnhorst, T., and DuBois, P., (1986). FEM-crash Berechnung eines Fahrzeug frontalaufpralls, VDI-Tagung: Berechnung im Automobilbau, 613, pp. 479-505.

[18] Jenefeldt, F., Thomson, R., (2004). A methodology to assess frontal stiffness to improve crash compatibility, International Journal of Crashworthiness, 9, pp. 475-482.

[19] Thomson, R., Edwards, M., Martin, T., van der Zweep, C., Damm, R., della Valle, G., (2007). Car-car crash compatibility: Development of crash test procedures in the VC-Compat project, International Journal of Crashworthiness, 12, pp. $137-151$.

[20] Pawlus, W., Nielsen, J. E., Karimi, H. R., Robbersmyr, K. G., (2010). Mathematical modeling and analysis of a vehicle crash, Proceedings of the 4th European Computing Conference, pp. 194-199.

[21] York, R., Day, T. R., (1999). The DyMESH method for three-dimensional multi-vehicle collision simulation. SAE Technical Papers.

[22] Happian-Smith, J., (2002). An introduction to modern vehicle design, Reed Educational and Professional Publishing Ltd., Oxford.

[23] Genta, G., (1997). Motor vehicle dynamics: modelling and simulation, World Scientific, London.

[24] Soltani, M., Topa, A., Karim, M. R., Sulong, N. R., (2016). Crashworthiness of G4 (2W) guardrail system: a finite element parametric study, International Journal of Crashworthiness, pp. 1-21.

[25] Mongiardini, M., Grzebieta, R. H., Mattos, G. A., \& Bambach, M. R., (2015). Computer modelling of vehicle rollover crash tests conducted with the UNSW Jordan Rollover System, International Journal of Crashworthiness, pp. 1-18.

[26] Ohashi, M., (1982). Future trend of automobile and the high strength sheet steel, Tetsu-to-Hagané, 68(9), pp. 1136-1146.

[27] Hallquist, J. O., (2007). LS-DYNA keyword user's manual, Livermore Software Technology Corporation, 970.

[28] Nagurbabu, N., (2010). Computational analysis for improved design of an SAE BAJA frame structure, Master thesis, University of Nevada, Las Vegas. 